\title{
PENGARUH STIMULAN AKAR DAN MEDIA TUMBUH PADA PERTUMBUHAN SETEK PUCUK PUNAK (Tetramerista glabra Miq)
}

\author{
(Effects of root stimulantand growth media on the growth of the cutting of punak shoot \\ (Tetramerista glabra Miq))
}

\author{
Anis Fatul Azizah, Abdurrani Muin, Hanna Artuti Ekamawanti \\ Fakultas Kehutanan Universitas Tanjungpura Pontianak. J1. Daya Nasional Pontianak 78124 \\ Email: azizahafa.untan14@gmail.com
}

\begin{abstract}
Punak (Tetramerista glabra Miq) is an indigenous plant species growing in peat swamp forest that can be propagated vegetatively through shoot cuttings. Punak can be used as a material for plywood,boards, poles, and firewood. The purpose of this study was to obtain root stimulants and growth media to be suitable for the growth of punak shoot cuttings. This research was conducted at the Silviculture Laboratory and screen house of the Ruang Pamer and Bursa Anggrek, UniversitasTanjungpura.This study used split plot design with a completely randomized design (CRD). The main plot factor was growth media with two levels of factor (cocopeat and cocopeat + husk charcoal) and the sub plot factor was root stimulants with three levels of factor (without root stimulants, rootone- $F$, and wood vinegar). The results of this study show that the percentage of life of shoot cuttings was $80 \%$, while the percentage of cuttings was rooted at $66.66 \%$. Therefore, the effect of root stimulant and growth media are not significant in the growth of punak shoot cuttings, as seen from the time of planting until threemonth-observation.
\end{abstract}

Keywords: cocopeat, husk charcoal, peat, restoration, wood vinegar

\section{PENDAHULUAN}

Keberadaan hutan rawa gambut mempunyai peran penting dalam menjaga ekosistem terutama hidrologi, pelestarian berbagaitumbuhan dan satwa liar. Namun sebagaian hutan rawa tersebut sudah banyak terdegradasi sehingga perlu dilakukan restorasi, untuk merestorasi hutan rawa gambut dalam rangka pelestarian hutan tersebut, maka restorasi harus dilakukan dengan menanam jenis-jenis lokal termasuk punak (Tetramerista glabra Miq). Menurut Alimah (2014) punak merupakan jenis kayu komersial, berkerapatan tinggi, tahan terhadap serangan rayap, dan mudah pemesinannya. Kayu punak digunakan untuk pagar, papan, tiang dan kayu api.
Kegiatan merestorasi hutan yang telah terdegrasi tidak lepas dari penyediaan bibit dalam jumlah banyak dengan kualitas yang memadai dan tepat waktu. Hasil survei pendahuluan menunjukkan biji punak tidak ditemukan di lokasi tersebut. Hal ini diduga karena musim berbuah tidak setiap waktu, sehingga untuk penyediaan bibit maka harus dilakukan secara vegetatif. Faktor yang mempengaruhi keberhasilan setek pucuk adalah lingkungan seperti media tumbuh, suhu, kelembapan, intensitas cahaya matahari dan zat pengatur tumbuh. Utami et al. (2005) menyatakan bahwa media setek yang umum digunakan adalah topsoil, pasir, atau campuran pasir dan pupuk organik. 
Alternatif lain sebagai media setek pucuk adalah cocopeat dan cocopeat campur arang sekam padi untuk menggantikan topsoil dan pasir. Menurut Sudomoet al. (2013) untuk mempercepat keberhasilan pembiakan secara vegetatif, perlu zat pengatur tumbuh dalam membantu tumbuhnya perakaran. Alternatif dari hasil diskusi bahwa cuka kayu berpotensi untuk digunakan mestimulasi pertumbuhan akar. Masalahnya sampai sekarang belum ada informasi mengenai media cocopeat dan cocopeat + arang sekam serta stimulan akar rootone $\mathrm{F}$ dan cuka kayu yang terbaik untuk pertumbuhan setek pucuk punak.

Tujuan penelitian mendapatkan stimulan akar dan media tumbuh yang sesuai untuk pertumbuhan setek pucuk punak.Manfaat penelitian untuk pengembangan ilmu pengetahuan Silvikultur khususnya tentang pembuatan setek pucuk punak dengan menggunakan perlakuan stimulan akar dan media tumbuh cuka kayu, rootone $\mathrm{F}$ dan media tanam cocopeat serta cocopeat campur arang sekam.

\section{METODOLOGI}

Penelitian ini dilaksanakan di Laboratorium Silvikultur Fakultas Kehutanan dan rumah kasa ruang pamer dan bursa anggrek Lembaga Penelitian Universitas Tanjungpura Pontianak, selama 3 bulan. Penelitian ini menggunakan metode eksperimen dengan rancangan petak terpisah (split plot) dengan pola dasar Rancangan Acak Lengkap (RAL). Perlakuan yang ditempatkan sebagai petak utama yaitu media tanam (M) terdiri dari cocopeat $\left(\mathrm{M}_{1}\right)$, cocopeat + arang sekam $\left(\mathrm{M}_{2}\right)$. Sebagai anak petak yaitu stimulan akar (Z), terdiri dari kontrol $\left(Z_{1}\right)$, rootone-F $\left(\mathrm{Z}_{2}\right)$, cuka kayu $\left(\mathrm{Z}_{3}\right), 6$ kombinasi perlakuan yaitucocopeat + kontrol $\left(\mathrm{M}_{1} \mathrm{Z}_{1}\right)$, cocopeat + rootone-F $\left(\mathrm{M}_{1} \mathrm{Z}_{2}\right)$, cocopeat + cuka kayu $\left(\mathrm{M}_{1} \mathrm{Z}_{3}\right)$, cocopeat dan arang sekam + kontrol $\left(\mathrm{M}_{2} \mathrm{Z}_{1}\right)$, cocopeat dan arang sekam + rootone-F $\left(\mathrm{M}_{2} \mathrm{Z}_{2}\right)$, cocopeat dan arang sekam + cuka kayu $\left(\mathrm{M}_{2} \mathrm{Z}_{3}\right)$.

Data utama dalam penelitian adalah: jumlah akar primer (helai), panjang akar primer (cm), jumlah akar sekunder (helai), jumlah daun dan persentase hidup (\%). Data penunjang adalah suhu udara $\left({ }^{\circ} \mathrm{C}\right)$ dan kelembapan (\%). Sebelum dianalisis ragam akan dilakukan uji asumsi kehomogenan menggunakan Uji Bartlett (Gaspersz 1994). Setelah diuji asumsi kehomogenan ragam kemudian dilanjutkan dengan analisis ragam, menggunakan rancangan percobaan petak terpisah dengan rancangan dasar RAL.

\section{HASIL DAN PEMBAHASAN}

Hasil penelitian menunjukkan bahwa stimulan akar dan media tumbuh tidak signifikan memengaruhi pertumbuhan setek pucuk punak selama tiga bulan pengamatan (Tabel 1). Variabel yang diukur meliputi persentase hidup (\%), persentase setek berakar(\%), jumlah akar primer (helai), jumlah akar sekunder (helai), panjang akar (cm) dan jumlah daun (helai). 
Tabel 1. Pengaruh media tumbuh dan stimulan akar pada pertumbuhan setek pucuk punak selama 12 minggu setelah tanam (MST) (The effect of growth media and root stimulant on growth of punak shoot cuttingsfor 12 weeks after planting)

\begin{tabular}{lcccc}
\hline Sumber Keragaman & $\begin{array}{l}\text { AAkar } \\
\text { Primer } \\
\text { (Helai) }\end{array}$ & $\begin{array}{l}\text { SAkar } \\
\text { Sekunder } \\
\text { (Helai) }\end{array}$ & $\begin{array}{l}\text { Panjang } \\
\text { Akar Primer } \\
\text { (cm) }\end{array}$ & $\begin{array}{l}\text { Jumlah } \\
\text { daun } \\
\text { (helai) }\end{array}$ \\
\hline Media Tanam & $3,81^{\text {tn }}$ & $1,58^{\text {tn }}$ & $0,21^{\text {tn }}$ & $0,83^{\text {tn }}$ \\
Stimulan Akar & $0,39^{\text {th }}$ & $0,39^{\text {tn }}$ & $0,31^{\text {tn }}$ & $1,06^{\text {tn }}$ \\
Interaksi (Media x Stimulan Akar) & $2,01^{\text {tn }}$ & $0,67^{\text {tn }}$ & $1,37^{\text {tn }}$ & $0,58^{\text {tn }}$ \\
\hline
\end{tabular}

Berdasarkan hasil penelitian 12 minggu di lapangan dapat dilihat pada Tabel 1 perlakuan stimulan akar dan media tumbuh yang telah diberikan tidak berpengaruh nyata terhadap pertumbuhansetek pucuk punak. Selama penelitian tiga bulan tidak semua setek yang diuji cobakan telah membentuk akar, diduga setek pucuk belum memberikan respon pertumbuhan perakaran yang maksimal berkaitan dengan jangka waktu pengamatan yang relatif pendek. Waktu pengamatan juga bisa ditambah (lebih lama) sehingga perakaran setek pucuk punak telah mencapai fase maksimal.Walaupun tidak berpengaruh nyata setek pucuk punak, yang tidak diberikan penambahan stimulan akar juga mampu tumbuh dengan baik. Hal ini menunjukan adanya perakaran dan munculnya tunas baru, karena hormon endogen dalam tanaman telah mencukupi untuk pertumbuhan akar primordial, sehingga pertumbuhan setek pucuk punak mampu bertahan hidup hingga akhir penelitian.

\section{Persentase Hidup Setek Pucuk Punak}

Persentase hidup setek merupakan perbandingan antara jumlah setek yang hidup pada akhir penelitian dengan jumlah bahan setek yang ditanam pada awal penelitian dikali dengan seratus persen. Persentase setek hidup dihitung berdasarkan pengamatan yang dilakukan pada (12 MST) salah satu tanda menunjukkan munculnya tunas baru. Berdasarkan jumlah setek yang masih segar (hidup) dan tidak memperlihatkan gejala kematian. Kriteria gejala kematian dalam pengamatan yaitu bahan setek mengalami gugur daun, daun yang kekuningan, dan bagian batang bawah yang mulai membusuk. Semakin tinggi persentasenya, maka semakin banyak bahan setek yang kemungkinan akan berakar, sehingga diakhir penelitian didapat persentase hidup tanaman berkisar $80 \%$. Persentase hidup setek menunjukkanbahan setek berpotensi untuk berakar dan menjadi bibit. 
Tabel 2. Rerata persentase hidup setek pucuk punak selama 12 minggusetelah tanam (MST)(The average life presentation of punak shoots cutting for 12 weeks after planting)

\begin{tabular}{ccccc}
\hline Media & \multicolumn{3}{c}{ Stimulan akar } & \multirow{2}{*}{ Rerata } \\
\cline { 2 - 4 } & Tanpa & Rootone F & Cuka kayu & \\
\hline & \multicolumn{3}{c}{ Persentase hidup setek (\%) } \\
Cocopeat & 60 & 80 & 60 & 66,67 \\
Cocopeat + arang sekam & 100 & 80 & 100 & 93,33 \\
\hline Rerata & 80 & 80 & 80 & 80 \\
\hline
\end{tabular}

Berdasarkan Tabel 2 persentase hidup setek pucuk pada media tanam cocopeat dan rootone $\mathrm{F}$ berkisar $80 \%$, sedangkan yang terendah yaitu penggunaan media cocopeat dengan kontrol dan cocopeat cuka kayu yaitu berkisar $60 \%$. Penggunaan media tanam cocopeat + arang sekam dengan kontrol dan cuka kayu rata-rata berkisar 100\%, sedangkan rerata terendah pada media cocopeat + arang sekam dan rootone $\mathrm{F}$ yaitu $80 \%$.Tanaman yang tidak diberi stimulan akar pun dapat hidup dan berakar yaitu 80 $\%$. Hal ini menunjukkan bahwa hormon endogen punak cukup untuk mestimulasi setek berakar, sehingga apabila ditambahkan dengan stimulan akar baik rootone $\mathrm{F}$ maupun cuka kayu tetap menghasilkan hasil yang sama. Apriani et al. (2015) menyatakan bahwa konsentrasi auksin hingga 40 ppm tidak dapat mempengaruhi peningkatan mutu bibit torbangun. Namun Sudomo et al. (2013) menjelaskan zat pengatur tumbuh (rootone-F) yang diberikan pada tanaman ditujukan untuk merangsang keluarnya akar, sehingga apabila diberikan pada tanaman yang terlalu tua hanya akan merangsang pembelahan sel saja yang ditandai dengan munculnya kalus pada luka bekas potongan. Penggunaan stimulan akar dan media tumbuh untuk setek pucuk memiliki rerata persentase hidup sama yaitu $80 \%$ pada media berbeda. Berdasarkan Tabel 1 pengaruh media dan stimulan akar pada ke empat variabel pengamatan yang diamati tidak nyata. Namun hasil penelitian Komarayati et al. (2014) menunjukkan bahwa penambahan cuka kayu 4\% dan arang $20 \%$ selama 6 (enam) bulan mampu menghasilkan tinggi dan diameter anakan pohon penghasil gaharu, masing-masing $72,20 \mathrm{~cm}$ dan 18,29 mm.Terbentuknya akar pada setek merupakan faktor penting, sebab akar dapat menyerap unsur hara dari dalam media dan dapat mendukung kelangsungan hidupnya. Hal ini sesuai dengan pernyataan Siregar (2010) bahwa faktor-faktor yang mempengaruhi tingkat keberhasilan setek terutama adalah faktor genetik, faktor lingkungan, media dan teknik pelaksanaan.

\section{Pertumbuhan Akar Setek Pucuk Punak}

Rerata pertumbuhan akar setek pucuk punak selama 12 minggu pengamatan tidak signifikan dipengaruhi oleh stimulan akar dan media tanam. Dimana penggunaan setimulan akar belum cukup untuk mestimulasi pertumbuhaan akar setek. Arinasa et al (2015) menyatakan bahwa interaksi antara konsentrasi rootone F dan panjang setek selama tiga bulan juga tidak berpengaruh nyata terhadap pertumbuhan bibit Begonia tuberosa Lmk. Menurut Ambarwati et al (2013) 
efektivitas cuka kayu selama 4 bulan sebayak $10 \mathrm{~mL}$ juga belum mampu menghasilkan pengaruh yang signifikan terhadap tinggi dan jumlah daun tanaman sawi. Hal ini dikarenakan setiap perlakuan yang diberikan termasuk kontrol memiliki sumber hormon auksin alami selain dari perlakuan yang diberikan yaitu hasil sintesis oleh tanaman itu sendiri, sehingga walaupun tanpa diberi penambahan hormon auksin setek tetap dapat melakukan perpanjangan akar, namun dengan proses yang lebih lama dan hasil yang lebih rendah. Begitu juga dengan media tanam setek yang digunakan. Hal ini sesuai dengan penelitian Pudjiono (2013) bahwa media tanam yang sama juga dapat memberikan pertumbuhan yang baik untuk setek pucuk manglid.

Tabel 3. Rerata pertumbuhan setek pucuk punak selama 12 minggu setelah tanam (MST) (The avarage growth rate of punakshoots cutting for 12 weeks after planting)

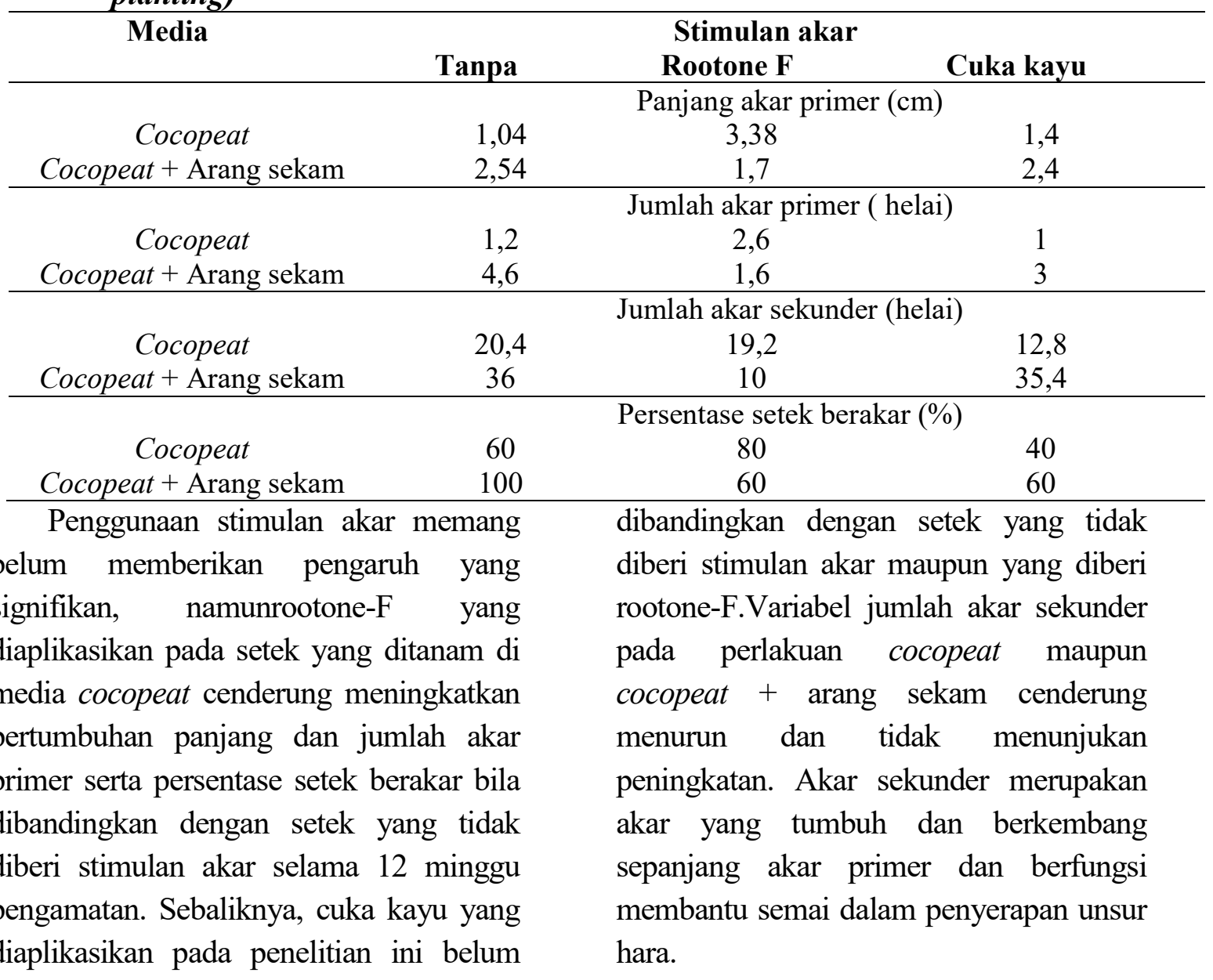

cukup menstimulasi pertumbuhan setek

a. b. c. 


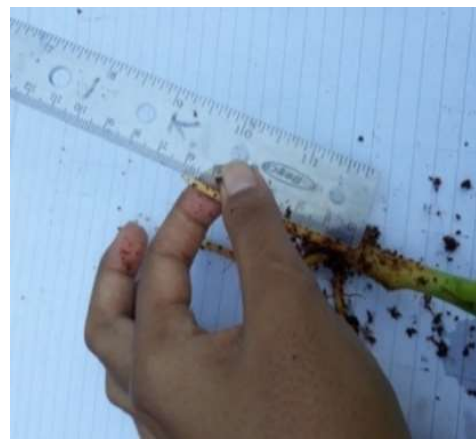

$\mathrm{a}$

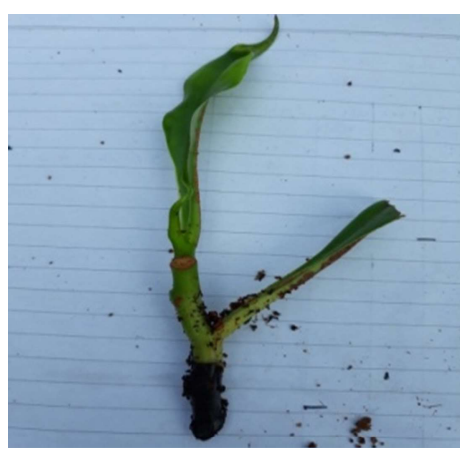

$\mathrm{b}$

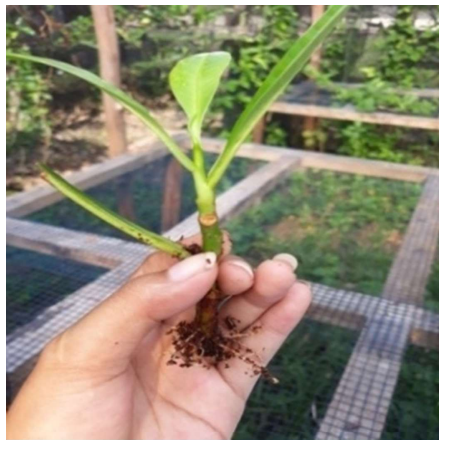

$\mathrm{c}$

Gambar 1.a.Panjang akar primer(the length of primary root), b. Setek tidak berakar (cutting without roots), c. Media cocopeat + arang sekam tanpa stimulan akar(cocopeat + husk charcoal without roots stimulant).

Setek punak yang diberi stimulan akar sintetis (rootone-F) cenderung menghasilkan perakaran yang baik, serta jumlah akarnya lebih banyak, namun yang diberi stimulan akar organik belum memberikan hasil yang serupa. Namun pada penelitian Nurlaeni et al. (2015) menunjukkan bahwa tidak ada perbedaan yang nyata antara ZPT organik dengan ZPT sintetik terhadap setek pucuk Camelia japonica. Putra et al. (2014) menyatakan bahwa rootone $\mathrm{F}$ dengan konsentrasi 200 ppm dapat memberikan laju pertumbuhan setek pucuk jabon yang baik dalam hal kemampuan bertunas, pertumbuhan akar, dan pertumbuhan jumlah daun. Persentase berakar setek merupakan hasil perbandingan antara setek yang hidup dan berakar pada akhir penelitian terhadap jumlah seluruh bahan setek yang ditanam. Pengamatan setek yang berakar dilakukan pada umur 12 MST (akhir penelitian). Beberapa setek yang hidup memperlihatkan kondisi yang masih berkalus dan belum muncul akar. Percobaan yang dilakukan dengan penggunan media yang berbeda bertujuan untuk melihat kemampuan media yang dapat mendukung dalam proses pembentukan akar bahan setek, karena media merupakan salah satu faktor penentu keberhasilan dari setek pucuk punak dalam proses pembentukan akar.

Campuran media cocopeat + arang sekam $(2: 1 \mathrm{v} / \mathrm{v})$ cenderung baik untuk perakaran setek punak, meskipun persentase setek berakar relatif rendah selama tiga bulan. namun penggunaan media cocopeat + arang sekam cenderung dapat meningkatkan persen hidup setek dibandingkan dengan media cocopeat. Media arang sekam tidak berpengaruh terhadap persentase jumlah akar sekunder maupun akar primer dalam mendukung pertumbuhan. Hal ini diduga arang sekam merupakan bahan steril sehingga tidak memuat kandungan hara yang dapat menunjang tanaman dalam menghasilkan kualitas pertumbuhan (Onggo et al. 2017). Cadangan makanan yang cukup pada 
bahan setek dibutuhkan untuk pembentukan akar.

\section{Pertumbuhan Daun Setek Pucuk Punak}

Jumlah daun yaitu semua daun yang muncul selama penelitian. Kondisi setek pucuk punak yang berasal dari semai hingga akhir pengamatan masih segar dengan warna daun yang masih hijau. Hal tersebut disebabkan bagian tanaman dibangun oleh jaringanjaringan muda, sehingga sangat mudah untuk merangsang keluarnya akar.
Kemampuan dan daya tahan hidup tanaman berbeda-beda merupakan salah satu faktor yang menyebabkan kematian tanaman. Hasil pengamatan selama penelitian menunjukkan setek dikatakan hidup jika mampu mengeluarkan akar dan tunas, namun jika yang tumbuh hanya salah satunya maka tanaman tersebut tidak akan bertahan lagi karena dapat mengalami proses kematian dengan ciri-ciri fisik yaitu warna daun menguning atau batang menghitam.

Tabel 4. Rerata Pertumbuhan Jumlah Daun Setek Pucuk Punak selama 12 minggu setelah tanam (MST) (The average of leaves growth of punak shoots cuttings for 12 weeks after planting)

\begin{tabular}{cccc}
\hline Media & Tanpa & $\begin{array}{c}\text { Stimulan akar } \\
\text { Rootone F }\end{array}$ & Cuka kayu \\
\hline & Jumlah daun (helai) & & \\
Cocopeat & 3,6 & 3,2 & 3,2 \\
Cocopeat + Arang sekam & 4,4 & 2,8 & 4,2 \\
\hline
\end{tabular}

Berdasarkan Tabel 4 dapat dilihat pada variabel jumlah daun cenderung menurun pertumbuhannya baik pada media cocopeat maupun cocopeat + arang sekam. Hasil rerata menunjukan tidak ada peningkatan jumlah daun selama 12 minggu. Kematian setek terjadi minggu ke-5 setelah penanaman, selama penelitian setek pucuk punak juga ditemui beberapa setek yang mengalami pembusukan dan kematian serta tumbuhnya jamur pada media tanam. Pembusukan setek tersebut ditandai dengan daun-daun setek yang mengalami perubahan warna menjadi kekuningan, selanjutnya menjadi kuning, hingga akhirnya batang berubah warna lagi menjadi kehitaman. Daundaun yang berwarna kehitaman tersebut selanjutnya gugur. Gaol et al. (2015) menjelaskan untuk dapat bertahan hidup maka setek memerlukan cadangan makanan dan hormon auksin endogen yang berasal dari bahan setek tersebut. Karbohidrat yang cukup pada setek pucuk punak membuat bahan tersebut dapat bertahan selama masa inisiasi akar. Hal ini diduga sumber karbohidrat masih terdapat pada bahan setek dan terus terbentuk, kemudian digunakan untuk pertumbuhan tunas baru dan akar. Setelah terbentuk tunas baru, proses inisiasi akar segera dimulai.

Supriyanto et al. (2014) menyatakan bahwa daun berfungi untuk proses fotosintesis sehingga dapat menghasilkan karbohidrat, sedangkan tunas berperan sebagai pusat penghasil auksin endogen yang berfungsi untuk menstimulir pembentukan akar. Yasman 
dan Hernawan (2002) menjelaskan sebenarnya hormon telah tersedia secara alami pada tumbuhan, namun tetap diberikan pada setek dengan tujuan meningkatkan kemampuan setek berakar, mempercepat proses pertumbuhan akar, meningkatkan jumlah dan kualitas akar.Hormon auksin yang dihasilkan dari pucuk akan ditranslokasikan ke bagian bawah setek melalui jaringan floem. Terakumulasinya hormon pada bagian setek akan membentuk kalus kemudian berkembang menjadi akar. Bahan setek yang diambil dari bagian tumbuhan yang berumur muda cenderung lebih mudah berakar, karena pada setek pucuk proses pembelahan dan pemanjangan sel akar lebih cepat .

Akhir penelitian terdapat tanaman yang mati, sehingga persentase hidup setek pucuk punak sebesar $80 \%$ dapat dikategorikan berhasil meskipun pengaruh perlakuan stimulan akar dan media tanam tidak signifikan. Rata-rata kelembapan udara relatif selama penelitian tiga bulan berkisar antara $29 \%-82,75 \%$ dan suhu udara rata-rata antara $25^{\circ} \mathrm{C}-36,75^{\circ} \mathrm{C}$. Menurut Cahyadi et al. (2017) kelembapan pada setek diusahakan konstan diatas 90\% terutama ketika setek belum mampu berakar. Pada penelitian ini menggunakan boks propagasi setek dan penyiraman rutin untuk menjaga kelembapan dalam boks tetap tinggi. Kelembapan yang relatif tinggi diperlukan dalam pembentukan akar. Hal ini bertujuan untuk mencegah terjadinya transpirasi yang berlebihan sehingga dapat menyebabkan kelayuan dan kematian setek. Suhu udara yang tepat untuk masing-masing tumbuhan berbeda-beda. Menurut Anam (2009) suhu yang optimum yaitu $24^{\circ} \mathrm{C}$, sehingga dapat merangsang pembelahan sel selama perakaran. Namun apabila suhu terlalu tinggi dan terlalu rendah dapat menyebabkan setek mati.

\section{Kesimpulan}

Media tumbuh dan stimulan akar yang sesuai belum diperoleh selama masa tiga bulan pertumbuhan setek pucuk punak. Namun, ada kecenderungan bahwa stimulan akar sintetis (rootone-F) sesuai digunakan pada setek punak yang ditanam di media cocopeat.

\section{Saran}

Penelitian stimulan akar yang lain perlu diujicobakan pada setek pucuk punak ini karena informasi mengenai perbanyakan tanaman jenis ini masih terbatas.

\section{UCAPAN TERIMA KASIH}

Terima kasih kepada SEAMEO BIOTROP telah membantu dana penelitian melalui Dr. Hanna Artuti Ekamawanti sebagai Ketua Penelitian DIPA Biotrop 2017, yangberjudul "Pengembangan Sistem Paludikultur untuk Lahan Gambut Terdegradasi: Karakteristik Lahan Gambut dan Teknik Propagasi Tumbuhan Indigenos".

\section{DAFTAR PUSTAKA}

Alimah D. 2014. Studi karakteristik dan potensi punak (Tetramerista glabra) sebagai jenis tanaman rawa gambut multiguna. Balai 
Penelitian Kehutanan Banjarbaru Galam7(2) : 1-8.

Ambarwati N, Subagiya, Pardjo YV. 2013. Efektifitas cuka kayu sebagai pestisida nabati dalam pengendalian hama Crocidolomia Pavonana dan zat perangsang tumbuh pada sawi. Jurnal Agrosains 15(1): 17-20

Anam C. 2009. Pengaruh dosis rootoneF dan bahan setek terhadap pertumbuhan setek bugenvil (Bougainvillea spectabilis L.). Jurnal Saintis 1(1) : 21-28.

Apriani P, Suhartanto MR. 2015. Peningkatan mutu bibit Torbangun (Plectranthus amboinicus Spreng) dengan pemilihan asal setek dan pemberian auksin . J. Hort. Indonesia 6(2): 109-115.

Arinasa, IBK. 2015. Pengaruh konsentrasi rootone $\mathrm{F}$ dan panjang setek pada pertumbuhan Begonia tuberosa Lmk. J. Hort 25(2) : 142-149.

Cahyadi O, Iskandar, AM, Ardian H. 2017. Pemberian rootone $\mathrm{F}$ terhadap pertumbuhan setek batang puri (Mitragyna speciosa Korth). Jurnal Hutan Lestari 5(2) : 191 - 199.

Gaol LAL, Meiriani, Purba E. 2015. Respons Pertumbuhan Setek Jeruk Nipis (Citrus aurantifolia Swingle) pada Berbagai Bahan Tanam dan Konsentrasi IBA (Indole Butyric Acid).Jurnal Agroekoteknologi4(1) :1815 1821.

Gaspersz V.1994. Metode Perancangan Percobaan. Bandung: CV. Armico.
Komarayati S. Gusmailina. Pari G. 2014. Pengaruh arang dan cuka kayu terhadap peningkatan pertumbuhan dan simpanan karbon. Jurnal Penelitian Hasil Hutan 32(1) : 313-328.

Nurlaeni Y, Sury MI. 2015. Respon setek pucuk Camelia japonica terhadap pemberian zatpengatur tumbuh organik. Pros Sem Nas Masy Biodiv Indon 1(5) : 12111215.

Onggo TM, Kusumiyati A, Nurfitriana AA. 2017. Pengaruh penambahan arang sekam dan ukuran polybag terhadap pertumbuhan dan hasil tanaman tomat kultivar 'Valouro' hasil sambung batang. Jurnal Kultivasi 16(1) : 298-304.

Pudjiono S. 2013. Pengaruh perbedaan media tanam terhadap perkembangan perakaran dan keberhasilan setek pucuk Manglid (Magnolia champaca var pubinervia (Blume) Figlar \& Noot). Balai Penelitian Pengembangan Bioteknologi Dan Pemuliaan Tanaman Hutan Yogyakarta 22-27.

Siregar N. 2010. Pengaruh bagian tunas terhadap pertumbuhan setek kranji (Pongamia pinnata Merril). Balai Penelitian Teknologi Perbenihan 1-10.

Sudomo A, Rohandi A, Mindawati N. 2013. Penggunaan zat pengatur tumbuh pada setek pucuk Manglid Bi rootone F. Jurnal Penelitian Hutan Tanaman 10(2) : 57-63.

Supriyanto, Prakas KE. 2014. Pengaruh pemberian zat pengatur tumbuh (rootone F) terhadap pertumbuhan setek Duabanga mollucana. 
JURNAL HUTAN LESTARI (2019)

Vol. 7 (1) : 472 - 481

Blume. Jurnal Silvikultur Tropika 05(2) : 97-103.

Putra F, Indriyanto, Riniarti M. 2014. Keberhasilan hidup setek pucuk jabon (Anthocephalus cadamba) dengan pemberian beberapa konsentrasi rootone-F. Jurnal Sylva Lestari 2(2) : 33-40.

Utami WN, Hoesen HSD, Witjaksono, Danu. 2005. Perbanyakan ulin (Eusideroxylon zwageri T.et.B) dengan bui dan setek. Berita Biologi 7(4) : 199-206.

Yasman I dan Hernawan. 2002. Manual Persemaian Dipterocarpaceae. Jakarta: Badan Litbang Kehutanan. 